\title{
LOS CRÉDITOS SINDICADOS Y LAS AGENCIAS DE CRÉDITOS Y GARANTÍAS EN LA REGULACIÓN DEL MERCADO DE CAPITALES CHILENO
}

\author{
SYNDICATED LOANS AND THE ADMINISTRATIVE AND COLLATERAL \\ AGENCIES IN THE REGULATION OF THE CHILEAN CAPITAL \\ MARKET
}

\section{Juan Luis Goldenberg Serrano*}

\begin{abstract}
RESUMEN: El mercado financiero ha consagrado diversas fórmulas para captar clientes con grandes necesidades de recursos, al mismo tiempo de crear mecanismos de diversificación del riesgo. Un punto clave en esta evolución ha sido el desarrollo del mercado de los créditos sindicados. Su surgimiento representa una respuesta natural a las crecientemente complejas necesidades de financiamiento por parte de deudores de gran tamaño. Permite una acción coordinada por parte de las instituciones financieras que desean mantener la independencia de sus créditos y limitar su exposición por medio de la dilución del riesgo. El crédito sindicado, fruto de la libertad de pactos, no tiene un reconocimiento directo por parte de nuestro ordenamiento jurídico, salvo en lo que se refiere -aunque ya indirectamente- a la unidad de gestión mediante las agencias de crédito y garantías, reguladas en la Ley No 20.190, de 5 de junio de 2007. A partir de dichas disposiciones y de la práctica comercial, el presente artículo pretende dar algunas primeras luces sobre su fisonomía y operatividad en el contexto del Derecho chileno.
\end{abstract}

Palabras clave: Créditos sindicados, agencia de crédito, agencia de garantías.

ABSTRACT: The financial markets have developed a variety of methods to cater for borrowers with substantial financing requirements, while simultaneously devising mechanisms for risk diversification. A key evolution was the development of the syndicated loans market. Its emergence represents a natural response to the increasingly complex financing needs of large borrowers. It permits coordinated action by financial institutions who wish to maintain independent borrowings and limit their exposure by diluting the risk. The syndicated loan, a result of the freedom of contract, is not currently recognized by our legal system other than by the indirect regulation of the administrative and collateral agencies, as governed by Law No. 20,190, of June $5^{\text {th }}, 2007$. On the basis of these rules and commercial practice, this article seeks to shed some light on the features and functionality of syndicated loans in the context of the Chilean law.

Key words: Syndicated loans, administrative agency, collateral agency.

\section{INTRODUCCIÓN}

Las operaciones financieras sindicadas (o, en términos más simples, los "créditos sindicados") son contratos en los que un grupo más o menos amplio de entidades (normalmente, instituciones financieras) prestan o se comprometen a prestar dinero a un único

\footnotetext{
* Profesor de Derecho Civil. Pontificia Universidad Católica de Chile. Licenciado en Derecho de la Pontificia Universidad Católica de Chile. Doctor en Derecho de la Universidad de Salamanca.
} 
deudor, bajo un contrato de base común que les permite unificar los términos generales del financiamiento y su actuación en la ejecución contractual, a la vez que se limitan los riesgos que cada una de dichas entidades está dispuesta a asumir. De este modo, la finalidad financiera que se pretende satisfacer hace insuficiente la regulación supletoria contenida en nuestro ordenamiento jurídico para tratar los supuestos de pluralidad de sujetos (en especial, en lo que se refiere al sujeto activo de la prestación), haciendo necesario añadir, al alero de la libertad contractual, un vasto número de estipulaciones que regulen la mecánica del contrato.

Esta estructura ha sido ampliamente utilizada en nuestro país, principalmente en los casos en los que las entidades bancarias han aunado sus esfuerzos para el financiamiento de proyectos con grandes necesidades de fondos. Sin embargo, la doctrina nacional escasamente se ha enfrentado al tema, dando cuenta de un vacío que la práctica ha debido llenar reflejando en los textos contractuales, casi a calco, el lenguaje de los negocios celebrados en el marco del Derecho anglosajón. Así, su formulación se basa en la redacción de un cúmulo de derechos, compromisos, obligaciones, restricciones y garantías que se cruzan con la mecánica común de cualquier operación de crédito de dinero.

Pero, ya desde una perspectiva jurídica, surgen varias dudas acerca de su configuración. Nuestro objetivo es, entonces, proponer una primera revisión de esta clase de financiamiento, centrándonos en un aspecto que nos parece esencial para la comprensión de su lógica: la tensión existente entre la diversificación del riesgo y la unidad de actuación de las entidades prestamistas. A partir de esta, creemos, se logran entender las estipulaciones contractuales que conforman la base de actuación de lo que en la práctica se denomina el "sindicato de acreedores", explicando, entre otras, las ideas de mancomunidad, proporcionalidad y cooperación, que serán objeto de nuestro estudio.

No obstante, un análisis pormenorizado de todas las fases y aspectos del crédito sindicado abarcaría demasiadas páginas como para poder condensarlas en un único artículo, a la vez que nos obligaría a descender a la multitud de variantes que nos presenta la práctica ${ }^{1}$. Por ello preferimos centrarnos en dos aspectos que nos parecen centrales en la comprensión del negocio, y que serán particularmente examinados para dar cuenta del objetivo propuesto: en primer lugar, la lógica financiera del contrato de crédito sindicado, que indiscutiblemente moldeará las estipulaciones contractuales insertas en los documentos de financiamiento (apartado II); y, luego, la regulación de las fórmulas de actuación conjunta de los acreedores, sea mediante la "agencia de crédito" o la "agencia de garantía", que constituyen el único extremo expresamente tratado por parte de nuestro ordenamiento jurídico a partir de la Ley No 20.190, de 5 de junio de 2007 (apartado III) 2.

\footnotetext{
1 En cualquier caso, la alusión al contrato de crédito sindicado no hace referencia a un único y rígido modelo de financiamiento, sino que se adecuará a las necesidades particulares del negocio, de modo que en el presente artículo solo hacemos referencia al formato más usual (pero no único) de esta clase de estructuras.

2 Si bien tal regulación no hace referencia directa a los créditos sindicados, es en este ámbito donde tradicionalmente estas formas de "agencia" han sido utilizadas en la práctica. Algún antecedente encontramos en el artículo 119 de la Ley $\mathrm{N}^{\circ} 18.045$, de 22 de octubre de 1981, que trata de la posibilidad de que las garantías sean perfeccionadas por el representante de los tenedores de bonos, al tiempo que también admite su sola individualización en las escrituras e inscripciones hipotecarias.
} 


\section{LA LÓGICA FINANCIERA DEL CRÉDITO SINDICADO}

El contrato de crédito sindicado es, ante todo, fruto de la libertad de pactos ${ }^{3}$. Las partes emplean una fórmula contractual básica (generalmente, una operación de crédito de dinero, regida por los términos de la Ley No 18.010, de 27 de junio de 1981), e introducen una serie de estipulaciones con miras a alcanzar la finalidad económica que pretenden satisfacer. De este modo, cada una de las obligaciones que el deudor adquiere con cada uno de los concedentes del crédito puede entenderse aisladamente bajo la idea de una operación de crédito de dinero, aun cuando se pacten ciertas obligaciones accesorias que responden a la existencia de una pluralidad de acreedores.

Pero cabe advertir que un gran porcentaje de tales estipulaciones no se refiere a una determinada conducta que debe desplegar el deudor ante las entidades prestamistas, sino especialmente a las formas en las que los diversos acreedores aunarán sus esfuerzos en la ejecución del contrato. Una parte considerable del texto contractual se dedicará a conformar el "sindicato de prestamistas", de modo que sus términos y condiciones particulares responden a un modelo particular, caracterizado esencialmente por la pluralidad de acreedores, las limitaciones de riesgo y el vínculo de colaboración. Sin embargo, si observamos cuidadosamente, estas características no logran desvirtuar los elementos esenciales de las operaciones de crédito, sino que solo conforman una estructura particular para reglar las relaciones internas entre la pluralidad de entidades prestamistas y su modo de actuación frente al prestatario.

La doctrina española se ha aventurado a dar ciertas definiciones de esta clase de contratos, apuntando a diversas características que parecen esenciales en este negocio jurídico atípico. En primer lugar, De Gispert la define como "una operación caracterizada por la intervención de una pluralidad de operadores bancarios en un único contrato de concesión de crédito, que por su cuantía y características excede de las posibilidades de atención por parte de un solo sujeto"4. Se destaca aquí el hecho de que al menos una de las partes del contrato (la parte activa) se encuentra constituida por una pluralidad de sujetos, todos con la cualidad común de tratarse de entidades bancarias, y la finalidad económica del contrato que pretende diluir los niveles de riesgo al cual cada uno de ellos está dispuesto a (o puede) exponerse.

Pero no nos parece una definición completa, en tanto la superación de los límites de riesgo por parte de cada entidad bancaria no deriva necesariamente en una estructura sindicada, sino, a lo más, en un esfuerzo de cofinanciamiento entre diferentes fuentes. En este último escenario, será labor del deudor buscar otros recursos para complementar sus necesidades económicas, sin que exista una particular relación o coordinación entre los diferentes financistas. Al contrario, estimamos que el núcleo del crédito sindicado se encuentra en la unidad de actuación y en la coordinación de intereses entre los diversos prestamistas, o, como describe Amesti, en el hecho de que "varias entidades bancarias, entre las que se encuentra la entidad que actúa como Banco agente -entidades acreditantes- se obligan a entregar, bien a poner a disposición del acreditado -a través del Banco agente- los fondos

3 Fernández de la Gándara (1997) p. 869.

4 De Gispert (1986) p. 3. 
hasta el límite y por el plazo estipulado, obligándose este, a su vez, al reembolso de dichos fondos y al pago de intereses, comisiones y gastos correspondientes, todo ello conforme a lo pactado en el contrato, con la particularidad que en algunos contratos, el acreditado podrá volver a utilizar los fondos reembolsados dentro del mismo periodo de disposición-apertura de crédito sindicado en cuenta corriente" 5 .

Creemos que esta definición tiene por virtud añadir el elemento adicional de la unidad de actuación de las entidades acreditantes, por medio de la figura especial del "banco agente". Sin embargo, la referencia a la forma específica en que el contrato de crédito sindicado se articula (esencialmente, una línea de crédito, rotativa (revolving) o no rotativa), solo se justifica en razón de tratarse de uno de los modelos más usuales ${ }^{6}$, pero no único, de operación sindicada. Un contrato de crédito sindicado puede suponer, al igual que cualquier operación de crédito de dinero, la entrega real del dinero al inicio de tiempo del perfeccionamiento del contrato o el mero compromiso de entrega bajo los términos y condiciones que determine el propio instrumento (artículo $1^{\circ}$ de la Ley No 18.010).

Una idea más genérica, pero no por ello imprecisa, es expresada por FerRé, quien define las operaciones bancarias sindicadas como "una operación activa promovida por un sujeto banquero requerido y autorizado por el futuro deudor, en la que la parte acreedora se integra por una pluralidad de sujetos que ostentan derechos independientes, pero que ejercen colectivamente a través de un representante irrevocable común"7. Esta definición destaca la tensión existente en toda operación sindicada entre la individualidad de los créditos y el vínculo de cooperación entre los acreedores sindicados, tensión que modelará la estructura contractual hasta situarlos en una posición bastante limítrofe entre la solidaridad activa y las obligaciones mancomunadas.

Ahora bien, históricamente, el crédito sindicado surge en el mercado financiero norteamericano a fin de permitir a las empresas la obtención de montos importantes de dinero cuando se han superado las exposiciones de riesgo a las que están dispuestas las entidades bancarias ${ }^{8}$. Dados los montos comprometidos, el deudor tendrá como alternativa de financiamiento el recurso al mercado de valores, en el sentido de obtención de fondos de parte de un amplio número de inversionistas, que logran diluir el riesgo por la sola adquisición de un monto determinado de las obligaciones (esencialmente, bonos) emitidos por el deudor. Pero esta fórmula puede ser bastante más compleja (y onerosa) de la que la entidad prestataria podría estar dispuesta a soportar, especialmente si no tiene experiencia en el mercado de valores, pero sí en el financiero.

De Gispert concluye entonces que "Un crédito sindicado constituye, en primer lugar, un mecanismo de limitación y división de riesgos" ". Las entidades bancarias, sea por limitaciones legales (artículo 84 del Decreto con Fuerza de Ley $N^{\circ} 3$, de 19 de diciembre de 1997, que contiene el texto refundido de la Ley General de Bancos) o sea por decisiones de

\footnotetext{
5 Amesti (1994) p. 408.

6 De Gispert (1986) p. 31.

7 Ferré (1998) p. 606.

8 Ferré (1998) p. 602.

9 De Gispert (1986) p. 38.
} 
riesgo internas (normalmente referidas al tipo de proyecto financiado y a las características del deudor), solo estarán dispuestas a participar en la operación de financiamiento hasta un cierto monto y bajo ciertas condiciones ${ }^{10}$. De hecho, la sindicación incluso resulta beneficiosa para las entidades financieras en tanto les permite ampliar el espectro de prestatarios que podrían encontrar actuando individualmente ${ }^{11}$.

El riesgo a diluir al que hacemos referencia es el denominado "riesgo comercial"12, referido a la eventualidad de incumplimiento o insolvencia del prestatario, supuestos que se acentúan considerando que el recurso a las operaciones bancarias sindicadas tiene sentido cuando los niveles de fondos requeridos por la empresa a financiar son ciertamente elevados y el proyecto probablemente no rendirá frutos como para sustentar el reembolso sino hasta un cierto (largo o mediano) plazo ${ }^{13}$.

Pero la limitación del riesgo no es la única variante que justifica la sindicación, sino también la necesidad de generar una unidad de actuación, resultando en un vínculo de cooperación entre las entidades acreditantes. Este, desde la perspectiva de las entidades prestamistas, disminuye los costos de supervisión y operación del contrato. Y, desde el punto de vista del prestatario, le permite el acceso a montos importantes de financiamiento y (normalmente) una relación directa con único interlocutor (el "banco agente"), al tiempo que generalmente supone que los términos básicos del contrato son iguales para todos los créditos que nazcan a su amparo ${ }^{14}$.

Pero la tirantez entre ambos extremos es evidente. Las entidades prestamistas no desearán que la reducción de costos que justifica la actuación unitaria desdibuje la individualidad de cada uno de los créditos, llevando a que las decisiones que escapan a la mera administración de los créditos no sean tomadas directamente por el "banco agente", sino por los propios acreedores, sea separadamente o conforme a la lógica de las mayorías. Esto último, especialmente en lo que se refiere a las circunstancias más delicadas de la relación, como decidir la modificación de sus términos financieros, la aceleración (o vencimiento anticipado) de la deuda, la demanda de incumplimiento o la ejecución de las garantías del crédito. A este sistema de mayorías se refiere precisamente el inciso segundo del artículo $5^{\circ}$ del artículo $18^{\circ}$ de la Ley $\mathrm{N}^{\circ} 20.190$, al disponer que "Se podrá acordar en el contrato que los acuerdos de los acreedores se adopten bajo el sistema de asambleas, que se llevarán a afecto según las formalidades que aquél disponga".

Esta tensión se aprecia también en las relaciones que se presentan entre los prestamistas, y en la forma en la que estas se configuran en el texto contractual ${ }^{15}$. Entonces,

\footnotetext{
10 Amesti (1994) p. 415.

11 Donaldson (1979) p. 89.

12 Blaise y Fouchard (1981) p. 157.

13 De hecho, la estructura del crédito sindicado también es utilizada como herramienta de refinanciamiento, en cuyo caso pueden reestructurarse los créditos independientes, vigentes en contra del deudor con un grupo de bancos, a modo de dejar de lado la lógica del cofinanciamiento.

14 Flaquer (1992) p. 109.

$15 \mathrm{Al}$ decir de Ferré (1998) p. 603, "La comunidad de acreedores, organizados pero independientes, dotada de un representante común, que conocemos como sindicato bancario, implica una peculiar forma del ejercicio asociado de distintos derchos dentro de un mismo contrato, que se proyecta sobre las propias financiaciones".
} 
este "ejercicio asociado" se compone considerando los extremos de individualidad y cooperación, que gira en torno a la idea del riesgo a menos en los siguientes sentidos: (i) la limitación del riesgo, conforme al régimen de mancomunidad; (ii) la posibilidad de desvinculación del riesgo, mediante la cesión del crédito; y (iii) la dilución del riesgo, conforme al régimen de proporcionalidad. A estos aspectos nos referiremos a continuación, mientras el vínculo de cooperación será tratado en el acápite III siguiente.

\subsection{LA LIMITACIÓN DEL RIESGO CONFORME AL RÉGIMEN DE LA MANCOMUNIDAD}

La idea de la limitación del riesgo en el marco del crédito sindicado responde a dos factores que deben reconducirse a la idea de la mancomunidad de las obligaciones asumidas a favor y por las entidades concedentes. Explicaremos separadamente cada uno de tales aspectos.

\subsubsection{Independencia de los créditos a favor de los prestamistas}

Desde el punto de vista activo, el contrato de crédito sindicado frecuentemente se estructura sobre la idea de términos y condiciones comunes a todos los créditos que surjan o puedan surgir de la relación entre prestamistas y prestatario. No suele haber distinción, entonces, en los plazos de restitución, las tasas y periodicidad de los intereses, las obligaciones adicionales ("covenants"), o las cláusulas de vencimiento anticipado, entre otros, de manera que la única diferencia entre los créditos estará condicionada por el monto que cada una de las entidades de crédito estuvo originalmente dispuesta a aportar para el financiamiento. Monto que aportará un dato crucial para la configuración del manejo común del crédito, sobre todo para el cálculo de las mayorías necesarias para decidir sobre los aspectos más delicados en el funcionamiento del contrato.

Suele haber, por decirlo de algún modo, una "causa común” entre todos los crédi$\operatorname{tos}^{16}$. Pero pese a esta unidad, que resulta en una clara reducción de costos de transacción, no puede implicar la existencia de una relación de solidaridad activa entre los diferentes acreedores ${ }^{17}$. De este modo, aun a pesar de la unidad buscada, los créditos que nazcan conforme a la mecánica del crédito sindicado se sujetarán necesariamente al régimen de las obligaciones simplemente conjuntas o mancomunadas. En consecuencia, cada acreedor solo podrá exigir el cumplimiento de su crédito, cuestión que indudablemente tendrá algún alcance en el régimen de garantías que asegure su cumplimiento.

Pero este régimen de mancomunidad, veremos, estará sujeto a ciertas matizaciones provenientes de dos factores esenciales en la construcción del crédito sindicado: (i) la unidad de actuación, sea por medio de las gestiones desempeñadas por el "banco agente" o por el "agente de garantías", según el caso; y (ii) la necesidad de dilución del riesgo, bajo la regla del reparto que usualmente determina que todo pago que se realice bajo este parti-

16 Amesti (1994) p. 418. Ferré (1998) p. 609 agrega que "Este negocio de cooperación tiene por causa la existencia de derechos de la misma naturaleza en el patrimonio de todos los acreedores. Los derechos de todos los partícipes se precisan con las mismas cláusulas y condiciones en los contratos. Este rasgo, esencial y común a toda sindicación, es presupuesto de la necesidad de colaboración especial que sienten los acreedores y que satisfacen mediante la actuación conjunta".

17 Respecto a los requisitos de la solidaridad, vid., por todos, Ramos Pazos (1999) pp. 84-86. 
cular esquema contractual debe ser distribuido entre todos los acreedores conforme a una proporción calculada en función al monto de los créditos otorgados.

\subsubsection{Independencia de las obligaciones asumidas por los prestamistas}

Hemos señalado que los contratos de crédito sindicado pueden configurarse alternativamente como operaciones de crédito o como operaciones de apertura de crédito. En este segundo caso, bastante habitual, la doctrina ha entendido que "el banco adquiere, en virtud de este contrato, la obligación de poner a disposición de su cliente determinada suma, por un tiempo prefijado o en forma indefinida, de acuerdo a las modalidades que se indican en el respectivo contrato" ${ }^{18}$. El objeto del contrato -añade ZunzuneGuI- no es la dación del crédito mismo, en el sentido de la entrega del dinero al cliente bancario, sino el crédito mismo como bien económico ${ }^{19}$.

En consecuencia, previo al desembolso del dinero en los términos expresados en el propio contrato de apertura de crédito, el cliente solo gozará de la facultad de efectuar disposiciones con cargo a la apertura. Por su parte, en esta fase preliminar, el banco ocupará la posición de deudor, en el sentido que se ha obligado con su cliente a proveer fondos, aunque siempre sujeto a los términos y condiciones prefijados en los documentos de financiamiento. O, como señala Garrigues, "el Banco asume la obligación de hacer honor a las órdenes del acreditado en cualquier momento y en cualquier cantidad, siempre que ambas estén dentro de los límites de tiempo y de suma pactados en el contrato" ${ }^{20}$. Tratándose de una estructura sindicada, las partes desearán aclarar que dicha obligación tiene el carácter de simplemente conjunta entre las entidades acreditantes ${ }^{21}$. De este modo, la cláusula de limitación del riesgo implicará que ninguna de las entidades prestamistas estará obligada ante el prestatario a desembolsar más fondos que los que originalmente ha estado dispuesto a conceder, ni aceptará un gravamen adicional como consecuencia de la eventual insolvencia de alguno de los demás concedentes ${ }^{22}$.

Por tanto, tampoco hay una obligación solidaria por parte de las entidades bancarias en el contexto de la apertura de crédito, dado que solo de este modo se podrá cumplir con la idea de limitación de riesgos que -entre otras variables- justifica la utilización de esta estructura contractual ${ }^{23}$. En breves palabras, "Las obligaciones asumidas por las entidades prestamistas frente al cliente tienen un carácter independiente o mancomunado. La ausencia de solidaridad reafirma uno de los propósitos perseguidos por la sindicación, cual es la

\footnotetext{
18 Puelma (1971) pp. 118 y 119.

19 Zunzunegui (2000) pp. 476 y 477.

20 Garrigues (1958) p. 207.

21 Más allá de la falta de una declaración contractual que, conforme a los términos del artículo 1.511 del Código Civil establezca una solidaridad convencional, la práctica dará cuenta de la frecuente inclusión de una cláusula de "declaración de mancomunidad de las obligaciones". Se desea que no quede asomo de duda de que las partes no desean someter sus relaciones jurídicas particulares a la regulación de las obligaciones solidarias, haciendo hincapié en su independencia y su sujeción a la escasísima regulación de las obligaciones simplemente conjuntas (FERNÁNDEZ de LA GÁNDARA (1997) p. 866).

22 Fernández de la Gándara (1997) p. 876.

23 De Gispert (1986) p. 46.
} 
redistribución del riesgo entre las entidades sindicadas... El régimen de mancomunidad permite fragmentar la prestación en tantas relaciones cuantas entidades participantes integren el sindicato de bancos"24.

En la práctica, la independencia de cada una de las obligaciones asumidas por las entidades prestamistas frente al deudor implicará que este último solo pueda dirigirse individualmente a cada uno de ellos para exigir su cumplimiento. Esta cuestión, que resulta medular en la redacción del contrato de crédito sindicado, tendrá especial importancia para el caso de que alguno de los bancos partícipes del sindicato - por cualquier motivo- no cumpla con su compromiso de poner a disposición del prestatario la suma por él acordada ${ }^{25}$. El "banco agente" podrá, a lo sumo, estar dispuesto a ejercer como mediador para instar por la correcta ejecución del contrato, pero normalmente no asumirá obligaciones ulteriores que supongan la búsqueda de nuevas fuentes de financiamiento ${ }^{26}$.

Finalmente, en caso de tratarse de un contrato de apertura de crédito, la división inicial del riesgo también implicará que el monto que deberá facilitar cada banco será el resultado de la proporción del monto solicitado por el deudor en relación con el compromiso asumido por la entidad bancaria en particular (a modo de tratamiento pari passu o pro rata treatment, conforme al lenguaje habitual de que dan cuenta Blaise y Fouchard) ${ }^{27}$. Esta cuestión puede sufrir algunas alteraciones en una determinada clase de créditos sindicados, gráficamente denominados "créditos subasta", en los que las entidades prestamistas compiten por otorgar el financiamiento (en mejores condiciones para el deudor), pero todavía al alero del contrato de crédito sindicado ${ }^{28}$.

\subsection{LA DESVINCULACIÓN DEL RIESGO MEDIANTE LA CESIÓN DEL CRÉDITO}

La "transferibilidad" del crédito sindicado constituye el elemento cronológicamente más reciente en la restructuración de esta forma de financiamiento ${ }^{29}$. La posibilidad de que cualquiera de los bancos prestamistas ceda su crédito en contra del deudor no se aleja de las reglas generales del Derecho de las obligaciones (artículos 1.901 y siguientes del Código Civil y 162 y siguientes del Código de Comercio). No se parece necesitar, a lo menos desde el punto de vista de su relación individual con el deudor, de una regulación contractual especial, bastando las reglas legales que requieren de la entrega del título y la notificación o aceptación del deudor para su perfeccionamiento. Pero sí tiene sentido referirnos a este punto en cuanto supone, por una parte, que las relaciones establecidas entre los miembros del sindicato de bancos puede, en algunos casos, considerarse como vínculos in tuito personae, y, por la otra, por sus implicaciones en el régimen de garantías (al menos) registrales.

La principal razón para hacer expresa referencia al régimen de cesión de los créditos por parte de las entidades acreditantes en el marco de esta clase de operaciones se justifica

\footnotetext{
24 TAPIA (2007) p. 758.

25 Blaise y Fouchard (1981) p. 159.

26 Aunque se ha propuesto que el "banco agente" asuma el incumplimiento de parte de cualquiera de los bancos partícipes y entregue los fondos faltantes al deudor (vid. Hughes (2006) p. 208).

27 Blaise y Fouchard (1981) p. 161.

28 Flaquer (1992) passim.

29 Hughes (2006) p. 119.
} 
en la creación de un mecanismo tendiente a facilitar tales disposiciones patrimoniales. Los créditos, especialmente por tratarse de operaciones a mediano o largo plazo, conllevan un nivel de riesgo que eventualmente alguno de los bancos puede ya no estar dispuesto a asumir. En una relación de financiamiento individual (en el sentido de no sindicada), la entidad acreditante no tendrá mayores limitaciones para desprenderse del crédito debido a que su relación se produce únicamente con el deudor. Sin embargo, una operación sindicada implica un grueso tejido de derechos y obligaciones con el resto de los acreedores, que podría traducirse en un obstáculo para lograr una eventual desvinculación del riesgo ${ }^{30}$.

Pero facilitar esta desvinculación debe ir aparejada con el hecho de que el cesionario del crédito deberá reconocer y dar cumplimiento a la estructura sindicada, asumiendo exactamente la misma posición jurídica que tenía el banco cedente. De este modo, la entidad cesionaria deberá asumir un cúmulo de obligaciones, mandatos, reglas de actuación común, entre otras, que en caso alguno pueden ser calificadas como obligaciones reales que pudiesen gravar al cesionario por la sola adquisición del crédito. Entonces, la cesión de la participación en la operación sindicada parecerá más bien una cesión de la posición contractual del banco cedente ${ }^{31}$.

En la esfera bancaria, esta cuestión ha tenido particular importancia -aunque bastante mayor en los sistemas norteamericano y europeo- dada la creación de un mercado secundario de obligaciones sindicadas ${ }^{32}$. E incluso como mecanismo para ceder no solo los créditos de los bancos partícipes, sino también para transferir sus obligaciones de provisión de fondos ("commitments") creadas conforme a los contratos de apertura de crédito ${ }^{33}$. Aunque en este último caso, generalmente se necesitaría de la aceptación y concurrencia del deudor ${ }^{34}$, especialmente cuando la relación entre el banco cedente y el deudor supone un vínculo de cooperación que supera la esfera de la simple relación crediticia.

En nuestro ordenamiento, en cambio, la única preocupación se ha dado mediante la introducción de una cierta regulación de la figura del "banco agente" y del "agente de garantías" que permite, por una parte, la estabilidad del mandato colectivo concedido a tales agentes, y, por la otra, que las cauciones sean constituidas a nombre del agente de modo que las cesiones efectuadas no requieran de nuevas inscripciones o anotaciones registrales.

Respecto al primer aspecto, el artículo $2^{\circ}$ del artículo $18^{\circ}$ de la Ley $N^{\circ} 20.190$, dispone que "La calidad de acreedor o deudor se puede tener al tiempo de celebrarse el contrato o adquirirse con posterioridad, por acuerdo entre las partes involucradas o por simple adhesión al contrato, de acuerdo con las formalidades y modalidades estipuladas en el mismo". En otras palabras, el mecanismo en virtud del cual el cesionario del crédito forma parte del contrato

\footnotetext{
30 Respecto a la posibilidad de cesión de contrato o de posiciones contractuales, vid., especialmente, FiguEROA Yáñez (2008) pp. 229-280; Ríos Labbé (2011), pp. 485-497. Dichos autores coinciden en la admisibilidad de la figura, como regla general, en nuestro ordenamiento jurídico, aunque deba prestarse especial atención a las limitaciones referidas a la cesión en contratos in tuito personae y al papel que juega el consentimiento del cedido para estos efectos.

31 Blaise y Fouchard (1981) pp. 167 y 171.

32 Para un análisis de las razones y estructuras de estos mercados, vid. RHodes (2004) pp. 495-512.

33 Hughes (2006) pp. 119 y 120.

34 Oldnall y Clark (2010) p. 89.
} 
de agencia de créditos y garantías queda dejado en manos del pacto que alcancen las partes, pudiendo consistir aquel, conforme expresa la propia norma, en un acuerdo de las partes involucradas o en la simple adhesión al contrato por parte del cesionario. La diferencia entre uno y otro medio parece encontrarse en el momento en que se consiente en la cesión de la posición contractual: en el primer escenario, el acuerdo de las partes interesadas (acreedores, deudor y banco agente) parece requerirse al tiempo de efectuarse la cesión, mientras en el segundo caso el consentimiento habrá sido otorgado anticipadamente en el propio texto del contrato de agencia.

Respecto a las garantías, se facilita la cesión de los créditos sindicados garantizados mediante la reducción de los costos que implicaría el registro de la cesión. De este modo, el artículo $7^{\circ}$ del artículo $18^{\circ}$ de la Ley No 20.190 dispone que "En los instrumentos de constitución y en las inscripciones de las cauciones que consistan en hipotecas o prendas que se acojan a esta agencia de garantías, no será necesario identificar a los acreedores, bastando individualizar el contrato y expresar el nombre del agente". Al respecto, obsérvese que la norma está redactada en términos facultativos, en el sentido de permitir la sola identificación del "agente de garantías", pero no prohíbe la designación de cada uno de los acreedores garantizados.

Cabe advertir que fue esta última cuestión la que motivó la dictación de reglas especiales respecto a la "agencia de garantías" en el marco de la reforma al mercado de capitales. Así se reveló en su trámite legislativo, conforme se dejó constancia en el primer informe de la Comisión de Hacienda de la Cámara de Diputados. En esta instancia, se señaló que "es práctica común en el extranjero que las participaciones de créditos se cedan fácilmente entre los bancos, pero en el caso de nuestro país la legislación nacional obligaría a efectuar, para cada cesión de una participación en un crédito, un sinfín de anotaciones e inscripciones en los distintos registros que resumen gran parte de las cauciones actualmente contempladas en ella" 35 .

De este modo, la cesión de los créditos garantizados no requerirá de nuevas gestiones, inscripciones o anotaciones, por cuanto el agente de garantías las habrá aceptado "por cuenta del conjunto de acreedores actuales y futuros". En el origen anglosajón de los créditos sindicados, esta cuestión usualmente se ha resuelto mediante la figura del trust (en este caso, un "security trust"). Esta figura tiene la ventaja de que los acreditantes tienen derechos sobre la garantía a la vez que les protege de los acreedores del agente. Al mismo tiempo implica que la transferencia de los créditos por parte de los acreedores resulta indiferente para los efectos de la garantía, en tanto esta no se encuentra constituida directamente en su beneficio (sino por medio del "trust"), de tal suerte que la cesión de los créditos no afectan la continuidad de la garantía ${ }^{36}$.

\subsection{LA DILUCIÓN DEL RIESGO CONFORME AL RÉGIMEN DE PROPORCIONALIDAD}

Sin perjuicio de lo indicado en los numerales anteriores, la "independencia de que goza cada banco en su posición deudora/acreedora no se da en el plano funcional de la relación

35 Primer informe de la Comisión de Hacienda de la Cámara de Diputados, recaído en el proyecto de la Ley No 20.190 (Boletín No. 3278-05), en primer trámite constitucional, de fecha 24 de octubre de 2003. Disponible en http://www.bcn.cl/histley/lfs/hdl-20190/HL20190.pdf, p. 158 [fecha de consulta: 5 de enero de 2012].

36 Mugasha (2007) p. 227. 
obligatoria, por cuanto es clara la existencia de una cierta comunidad de intereses y de riesgos frente a la otra parte contratante" 37 . Esta relación pretenderá diluir los riesgos de la operación entre todas las entidades involucradas, vinculándolos entre sí bajo la idea de cooperación.

Ello justifica la incorporación de ciertas estipulaciones que, como punto en común, buscan que ninguno de los bancos que forme parte del sindicato pueda verse relativamente favorecido o perjudicado por las decisiones de pago del deudor o por la mayor celeridad de alguno de los acreedores en el cobro de sus créditos. Estos pactos son: (i) la cláusula de distribución proporcional de los pagos por parte del "banco agente" ("pro rata payment clause"); (ii) la cláusula de "solidaridad" ("sharing clause"); y (iii) la unidad de garantías o el pacto de igualdad de rango de las garantías reales, según el caso.

La dilución y vinculación del riesgo se traducirá, en primer lugar, en que cualquier pago que no alcance a satisfacer las cuotas de cada uno de los bancos partícipes deberá ser distribuido proporcionalmente por parte del "banco agente" entre todos los prestamistas, de manera que ni este ni el deudor pueden pretender favorecer a un determinado acreedor mediante la realización de un pago individualizado ${ }^{38}$. Esta estipulación contractual supone que todos los pagos deben ser recibidos por parte del "banco agente", el que actuará como diputado de todas las entidades crediticias, en los términos de los artículos 1.580 y siguientes del Código Civil. Así, una de las funciones habituales del "banco agente" en ejercicio de la "agencia de créditos" será el efectuar los cálculos que deriven en el pago de la proporción que corresponde a cada uno de los miembros del sindicato, de modo de poder llevar a cabo la rendición de cuentas de su mandato.

Obsérvese, eso sí, que se trata de una estructura tomada del Derecho anglosajón, usualmente configurada al amparo de un trust, de modo que los bancos adquieren titularidad directa sobre los fondos recibidos por parte del agente, liberando a los bancos del riesgo de insolvencia. En Chile, la cuestión no se encuentra resuelta de igual modo, atendida la inexistencia de una figura análoga al trust (especialmente cuando se trata de dinero) y al recurso expreso al contrato de mandato.

Esta cláusula, sin embargo, no se presenta en todos los modelos de contratación sindicada, especialmente en los casos en los que se estima no ser necesaria por la posibilidad de ser reemplazada por la "cláusula de solidaridad" a la que haremos referencia a continuación. La ausencia de una distribución proporcional por parte del "banco agente" no implica un rechazo a la dilución de los riesgos, sino el reemplazo del modo en el que este es logrado, suponiendo suficientes los compromisos del deudor de efectuar los pagos a pro rata desde un inicio y de todos los acreedores de traspasar a los demás los montos recibidos que, por cualquier motivo, excedan la proporción que les corresponde.

Ahora bien, la llamada "cláusula de solidaridad" ("sharing clause") implica que las entidades prestamistas deben compartir (proporcionalmente) las cantidades recibidas de parte del deu-

37 De Gispert (1986) p. 47.

38 El texto de esta clase de cláusulas es habitualmente similar al siguiente: "El deudor deberá pagar el capital e intereses de los créditos adeudados a cada uno de los acreedores, a través del banco agente. Este distribuirá los pagos entre cada uno de los acreedores, a prorrata de su participación en los citados créditos, a más tardar al día hábil bancario siguiente al día en que el correspondiente pago hubiese sido efectuado por el deudor". 
dor con motivo de la satisfacción de los préstamos enmarcados en el crédito sindicado ${ }^{39}$. Esta cláusula no es incompatible con la anterior. Si bien los contratos de crédito sindicado suelen establecer que todos los pagos deben canalizarse por medio del "banco agente", este se comportará como un mero diputado de las entidades de crédito, de manera que podría argumentarse favorablemente la virtud liberatoria del pago efectuado en manos de cualquiera de los mandantes. Aunque podría indicarse que, de conformidad al artículo 1.584 del Código Civil, estamos frente a un supuesto en el que el diputado ha sido nombrado de común acuerdo entre acreedores y el deudor, normalmente irrevocable a la sola voluntad del acreedor. Pero el argumento debería avanzar hasta indicar que la recepción del pago de manera directa por el acreedor -en su calidad de mandante- a lo menos implica una revocación tácita de la diputación, cuestión que no parece ser aceptada en los términos del citado artículo, a menos que el deudor consienta en dicha revocación (consentimiento que podrá deducirse del solo hecho de haber efectuado un pago directo que ha obviado la posibilidad de pago por medio del diputado).

De este modo, y nuevamente a fin de evitar un beneficio indebido a favor de un determinado acreedor -que por proximidad o cualquier otra causa pudiese resultar injustamente preferido-, cada entidad bancaria se compromete a hacer entrega de la parte que les corresponda a las demás prestamistas en el pago efectuado, sea directamente o por medio del banco agente, conforme a la regla de la proporcionalidad ${ }^{40}$. Esta cláusula también tendrá operatividad en eventos en que han mediado otros modos de extinguir las obligaciones funcionalmente asimilables al pago, como son la dación en pago o la compensación, situaciones que también generarán la consecuente obligación de entrega a los demás miembros del sindicado por parte de la correspondiente entidad de crédito. Pero nuevamente se asoma aquí el riesgo de insolvencia que deben asumir los bancos en relación, esta vez, a las demás entidades de crédito.

Sobre la justificación de estas cláusulas, TaPIa y Ferré apuntan a su evidente proximidad con la idea de la contribución que supone la solidaridad, pese a tratarse de obligaciones simplemente conjuntas ${ }^{41}$. De este modo, se pretenden similares efectos que los que la solidaridad activa implica para las relaciones internas entre los acreedores, aunque solo para los pagos excesivos de la prorrata que a cada uno le corresponde ${ }^{42}$. Pero las entidades acreditantes no desearán someterse a todo el régimen jurídico de la solidaridad activa puesto que querrán mantener la independencia de sus créditos. No buscarán, por de pronto, que cualquiera de los prestamistas pueda dirigirse en contra del deudor a efectos de cobrar el total de la deuda, para luego entrar en el campo de la distribución del crédito entre ellos (artículo 1.511, inciso segundo del Código Civil) ${ }^{43}$. La distribución proporcional de los

39 Varios autores (TAPIA, 2007, p. 769; Ferré, 1998, p. 618).

40 Esta cláusula suele redactarse del siguiente modo: "En caso que el deudor hubiese efectuado algún pago en exceso a uno o más de los acreedores, dicho acreedor o acreedores indebidamente beneficiados deberán poner el exceso a disposición del banco agente dentro de los tres dias siguientes a la percepción de dicho pago en exceso, para que este, a su vez, pague proporcionalmente a los demás acreedores las cantidades que a cada uno corresponda".

41 TAPIA (2007) p. 769.

42 Sobre este efecto, vid. Ramos Pazos (1999) p. 93.

43 Lo anterior, además de los demás efectos legales de la solidaridad activa, como las consecuencias de la operatividad de los demás modos de extinguir las obligaciones. Sobre el particular, vid. Ramos Pazos (1999) pp. 92-93. 
créditos pretende la dilución del riesgo comercial, y forzarla, sobre todo en la esfera de la denominada "cláusula de solidaridad", tendrá lugar en eventos anómalos en los que, por algún motivo, esta dilución no ha sido respetada.

Finalmente, la "unidad de la garantía" o la cláusula de "igualdad de rango" tienen por objeto evitar una graduación de las garantías que se hayan constituido en el marco de la operación de crédito sindicado a favor de todas las entidades prestamistas. En esta clase de negocios, es habitual la constitución de cauciones para asegurar el buen resultado del financiamiento, especialmente para rebajar la exposición de riesgo de los acreedores. En estructuras de simples cofinanciamientos, los acreedores posteriores deberán respetar la existencia de las garantías anteriores, bajo la premisa del prior tempore, potior iure (artículo 2.477 del Código Civil en relación a la hipoteca y artículo 16 del artículo 14 de la Ley $\mathrm{N}^{\circ}$ 20.190 , en relación a la prenda sin desplazamiento). Sin embargo, en las operaciones sindicadas -considerando la necesidad de dilución del riesgo- tiene sentido que los acreedores gocen de igual grado de protección en virtud de la constitución de las citadas garantías.

Ello puede lograrse por medio de dos mecanismos alternativos: (i) se constituye una única garantía a favor de todos los prestamistas, que parece ser el modelo previsto por la Ley No 20.190, al disponer que todas las cauciones que "se constituyan se otorgarán a favor del agente, quien las aceptará por cuenta del conjunto de acreedores actuales y futuros" (artículo $3^{\circ}$, inciso tercero, del artículo $18^{\circ}$ de la Ley No 20.190). Tal unidad supondrá la creación de un único derecho real de garantía que será compartido en comunidad por parte de los acreedores garantizados, cuya constitución, conservación, administración y ejecución son confiadas a su mandatario; o (ii) se constituye una garantía a favor de cada uno de los miembros de sindicato, pero se pacta convencionalmente su "igualdad de rango", en términos de desplazar la aplicación de la regla de temporalidad de las garantías reales ${ }^{44}$. Ello podrá hacerse en el entendido de que dicha regla tiene un carácter supletorio (en el sentido de no ser "de orden público"), admitiendo pacto en contrario.

\section{FÓRMULAS DE ACTUACIÓN CONJUNTA EN EL CRÉDITO SINDICADO}

\subsection{El vínculo de COOPERACión MANifEstado Mediante la UNidAd DE ACTUACIÓN}

La unidad aparente de los créditos también dará paso a una actuación común. En una estructura sindicada los prestamistas suelen actuar ante el deudor por medio de una única cara visible, el "banco agente", que, entre otras funciones, estará encargado de servir de mediador entre las partes en toda necesidad de notificación, determinación de la tasa de interés variable aplicable a cada periodo de intereses, distribución de los pagos, entre otras. En la práctica, el "banco agente" suele ser el que ha participado en una etapa precontrac-

\footnotetext{
44 La redacción de esta clase de cláusulas suele plantearse del siguiente modo: "Esta garantía se constituye en comun a favor de todos los acreedores, en igual grado, sin preferencia entre ellos, cualquiera que sea el orden en que se les mencione en esta escritura, o en las publicaciones o inscripciones que se verifiquen con ocasión de dicha garantía. De este modo, los acreedores concurrirán con igual grado de preferencia ante una eventual ejecución, concurso de acreedores y/o liquidación de la respectiva garantía, de conformidad con los montos efectivamente adeudados a cada uno de ellos".
} 
tual, ejerciendo funciones de asesor financiero y negociado el tenor general del contrato con el prestatario (como "lead arranger"), siendo lógico que siga siendo el representante del sindicato de bancos ante el deudor ${ }^{45}$.

A este respecto, creemos que, aun cuando el mensaje de la Ley No 20.190 solo hacía alusión a la agencia de garantías, la modificación incluida (sin mayores explicaciones) en la Comisión de Hacienda de la Cámara de Diputados, terminó por hacer referencia también a esta forma especial de mandato ${ }^{46}$. Solo de este modo podemos entender la distinción entre la "agencia de créditos" y la "agencia de garantías" planteada en el artículo $1^{\circ}$ del artículo $18^{\circ}$ de la citada ley. En este sentido, aún cuando la mayor parte de las disposiciones siguientes únicamente pretenden resolver los problemas prácticos generados por la constitución de garantías comunes, gran parte de su régimen jurídico es aplicable a ambas formas de "agencia".

Sin perjuicio de lo anterior, bien vale la pena puntualizar que, de conformidad al citado artículo $1^{\circ}$, existirá una "agencia de créditos" cuando la fórmula contractual haya designado un mandatario común para el otorgamiento o gestión de los créditos y para el ejercicio mancomunado de los derechos que de ellos emanen ${ }^{47}$. Sin embargo, la unidad de actuación por medio del "banco agente" cesará en situaciones extraordinarias 48 (que escapan de la mera gestión del financiamiento), de tal suerte que bien podemos concluir que la gestión conjunta efectuada por este agente solo tiene sentido en la fase operativa del crédito, pero tiende a perderla en su eventual fase patológica ${ }^{49}$. Así, FERNÁNDEZ DE LA GÁNDARA describe que el elenco de las funciones del "banco agente" se circunscribe únicamente al ámbito administrativo del contrato, de tal suerte que las decisiones que escapan a la gestión de los créditos deben ser tomadas conjuntamente con los demás bancos acreditantes ${ }^{50}$. Elemento que también debe ser tomado en cuenta en las recurrentes cláusulas de limitación de responsabilidad del "banco agente", haciéndolo normalmente responsable solo de la culpa grave y el dolo.

Por tanto, la aparente unidad se fractura cuando cada prestamista debe velar por sus propios intereses, especialmente cuando se ha apreciado un quebrantamiento de alguna de

45 Conforme describe TAPia (2007) p. 756 "La operación se estructura en dos fases: la fase precontractual, que se inicia por el encargo de un cliente a un banco de organizar la operación de préstamo sindicado y donde tiene lugar la formación del sindicato de bancos; y la fase de vida del préstamo, que se inicia con la celebración del contrato y donde el lead manager -habitualmente convertido en Banco agente- desempeña un importante papel como comisionista de la operación”.

46 Ver Informe de la Comisión de Hacienda del Senado, recaído en el proyecto de la Ley N²0.190 (Boletín No. 3278-05), en segundo trámite constitucional, de fecha 27 de octubre de 2006. Disponible en http://www. bcn.cl/histley/lfs/hdl-20190/HL20190.pdf, pp. 1.053 y 1.054 [fecha de consulta: 5 de enero de 2012].

47 Como bien resume De Gispert (1986) pp. 79 y 80, “Ante todo, el Banco Agente es quien canaliza las sucesivas fases de ejecución del crédito. Ello significa que recibe las solicitudes de disposición por parte del acreditado, comunica a los bancos las cantidades que le deben remitir, y procede a su transferencia al solicitante. Por otra parte, centraliza asimismo los pagos que el acreditado debe realizar en concepto de devolución del principal, intereses, comisiones y gastos, y los distribuye entre los miembros del consorcio en proporción a sus participaciones recíprocas".

48 FERré (1998) p. 609.

49 Así ocurre también en los casos en los que se desean modificar los términos del contrato, de suerte que ello será decisión de los bancos, actuando directamente, sin que ello quede dentro del ámbito de actuación del Banco agente.

50 Fernández de la Gándara (1997) p. 877. 
las cláusulas contractuales por parte del deudor, este ha caído en insolvencia o ha incumplido específicamente con sus obligaciones de pago. En estos casos, la actuación del "banco agente" suele ser reemplazada por un régimen de mayorías ${ }^{51}$, solución que es reconocida en el inciso segundo del artículo $5^{\circ}$ del artículo $18^{\circ}$ de la Ley $\mathrm{N}^{\circ} 20.190$, al que ya hemos hecho referencia. $\mathrm{O}$, incluso, aunque en casos más extremos, la unidad de actuación puede ser completamente desplazada, dejando en manos de cada uno de los bancos su decisión respecto al futuro de cada uno de sus créditos ${ }^{52}$.

En estas circunstancias volvemos entonces a la idea de individualidad y autonomía de cada una de las operaciones bancarias. Ello, sin perjuicio de que la propia estructura del crédito sindicado ofrezca mecanismos de solución colectiva -que serán los que revelen el afán aún cooperador de los bancos sindicados-, intentando preservar una actuación conjunta sea para resolver el contrato, para demandar su cumplimiento y/o ejecutar sus garantías. Solo en caso en que este esfuerzo sea infructuoso, generalmente se permite a cada entidad acreditante volver a la lógica de la actuación individual ${ }^{53}$.

Esta unidad de actuación tiene una especial particularidad al tratar de la constitución, conservación y ejecución de las garantías reales que aseguren conjuntamente cada uno de los créditos nacidos al amparo de las operaciones de crédito sindicado, pudiendo contar o no con un mandatario especial que recibe el nombre de "agente de garantías". En estos supuestos, corresponderá al "agente de garantías" realizar las actuaciones que lleven al perfeccionamiento de las garantías, como también intervenir en las gestiones que se refieran a la modificación y alzamiento de las mismas.

\subsection{Aspectos RELEVANTES DEL RÉGIMEN JURÍdico DE LAS AGENCIAS “DE CRÉdito” Y “DE Garantías" en El Derecho Chileno}

Ya hemos señalado que podemos hablar de un cierto reconocimiento indirecto de los créditos sindicados por medio de la regulación incorporada en nuestro ordenamiento por parte de la Ley $\mathrm{N}^{\circ}$ 20.190. Sobre este particular, no nos interesa (al menos por el momento) descender a toda la problemática jurídica que generan las agencias tipificadas en dicha normativa. Al contrario, solo pretendemos dar cuenta de los aspectos que hemos considerado relevantes para la explicación de la lógica del crédito sindicado -a la que hemos hecho referencia en el epígrafe anterior- y a su articulación práctica por medio de esta clase especial de mandatarios.

\subsubsection{Sobre la naturaleza de las agencias "de crédito" y "de garantías"}

Como dispone el artículo $1^{\circ}$ del artículo $18^{\circ}$ de la Ley $\mathrm{N}^{\circ} 20.190$, la "agencia de garantías" (al igual que la "agencia de créditos") es esencialmente un mandato. Ya puntualiza TAPIA que el sindicato de bancos no posee personalidad jurídica, de manera que ningún tipo de agente podrá entenderse como un órgano de dicho sindicato, sino que actuará

\footnotetext{
51 De Gispert (1986) p. 38.

52 Para una referencia a las tendencias actuales para el régimen de actuación conjunta sobre la base de mayorías, vid. RaWlings (2009) passim.

53 Rhodes (2004) p. 14.
} 
siempre a nombre y riesgo de cada uno de sus representantes ${ }^{54}$. La asociación de intereses entre los bancos, entonces, no logra configurarse como ninguna de las fórmulas asociativas típicas que ofrece el ordenamiento jurídico ${ }^{55}$, lo que implica que la expresión de voluntad por parte del agente será necesariamente efectuada en nombre de cada uno de sus mandantes, sin referirse a la manifestación de una voluntad sindical.

La doctrina comparada ya había llegado a un cierto consenso que la figura del agente -aunque referido principalmente al "banco agente" - se construye desde la figura de la comisión mercantil ${ }^{56}$, como termina por corroborar el artículo $1^{\circ}$ antes citado. A la misma conclusión podía llegarse en el ordenamiento jurídico chileno si se toma en consideración que, conforme al artículo 233 del Código de Comercio, "el mandato comercial es un contrato por el cual una persona encarga la ejecución de uno o más negocios lícitos de comercio a otra que se obliga a administrarlos gratuitamente o mediante una retribución y a dar cuenta de su desempeño", y que el negocio encargado se refiere a una operación bancaria, recogida en el numeral 11 del artículo $3^{\circ}$ del mismo cuerpo legal.

Así, el ejercicio de las actividades del agente queda sometido a la regulación contenida en los artículos 233 y siguientes del Código de Comercio ${ }^{57}$, sin perjuicio de las disposiciones supletorias de los artículos 2.116 y siguientes del Código Civil y de las reglas especiales contenidas en el propio acuerdo contractual. Sin embargo, las principales reglas aplicables -sean especiales o generales- han sido establecidas de modo supletorio, lo cual es revelado por la continua referencia al carácter dispositivo de ciertas normas dispuestas en el artículo $18^{\circ}$ de la Ley $\mathrm{N}^{\circ} 20.190$.

\subsubsection{Sobre las características de las agencias de "crédito" y de "garantías"}

Esta especie de mandato (o "agencia", como parece preferir denominarla el legislador para seguir la nomenclatura importada de la práctica anglosajona) tiene varias características especiales que bien vale la pena revisar a la luz de las disposiciones contenidas en el referido artículo $18^{\circ}$.

a. Pluralidad de comitentes

Se trata de un mandato caracterizado por su colectividad, en el sentido que la parte mandante está constituida por una pluralidad de entidades (comitentes) que actúan por medio de un comisionista único y común. Esta posibilidad ya estaba admitida en el artículo 2.126 del Código Civil, aunque dicha regulación no descienda a las particularidades propias de la pluralidad de mandantes, haciendo necesario someterse al régimen general de las obligaciones con pluralidad de sujetos.

Son dos las consecuencias que consideramos importante destacar a este respecto: en primer lugar, la mayor parte de las obligaciones asumidas por el mandatario constituyen

\footnotetext{
4 TAPIA (2007) p. 758.

55 Amesti (1994) p. 420.

56 Varios autores (De Gispert, 1986, p. 72; Fernández de la GÁndara, 1997, p. 866; TApia, 2007, p. 756).

57 Para un panorama general de las reglas aplicables a la comisión mercantil, vid. Contreras Strauch (2005) pp. 619-634.
} 
"obligaciones de hacer" que requieren de una ejecución completa para la satisfacción del encargo, y, por tanto, pueden estimarse indivisibles (artículo 1.524 del Código Civil), de manera tal que cualquiera de los mandantes puede solicitar el cumplimiento íntegro de la prestación. Una excepción fundamental debemos apuntar en el caso de que se haya encomendado al "banco agente" la diputación para el pago de las obligaciones o en el evento que el "agente de garantías" reciba el producto de la ejecución de las cauciones. En estos casos, el resultado de sus gestiones deberá ser entregado a cada uno de los bancos partícipes a título de "rendición de cuentas" (artículos 50 del artículo 18º de la Ley No 20.190, 279 del Código de Comercio y 2.155 del Código Civil), y, como tal, debe entenderse como una "obligación de dar". La divisibilidad de esta obligación implicará que cada uno de los bancos partícipes solo podrá reclamar el cumplimiento de su respectiva obligación, en tanto no nos encontramos ante un supuesto de solidaridad activa.

Luego, tratándose de una comisión mercantil (y aplicando la normativa correspondiente a este tipo contractual conforme a la remisión expresa en el inciso final del artículo $1^{\circ}$ del artículo $18^{\circ}$ de la Ley $N^{\circ} 20.190$ ), el artículo 290 del Código de Comercio dispone que la comisión colectivamente conferida por muchos mandantes produce entre ellos obligaciones solidarias a favor del comisionista, aspecto de especial relevancia si se considera el deseo de individualidad de los bancos acreedores pese a la estructura del crédito sindicado ${ }^{58}$. Como detalla Stitchkin, "Obsérvese que se trata de un caso de solidaridad legal pasiva $-\mathrm{y}$ no activa, como algunos han pretendido-, pues se establece a favor del comisionista que aparece como acreedor de sus mandantes por las prestaciones que les deban, remuneración, reembolso de anticipo, etc." ${ }^{59}$.

En cualquier caso, consideramos que esta especie de solidaridad legal -como toda solidaridad (artículo 1.516 del Código Civil) - puede ser válidamente renunciada por el "banco agente" o el "agente de garantías", según el caso, a favor de quienes se ha establecido. Ello, en aplicación de los términos generales del artículo 12 del Código Civil, implicando, como agrega el inciso final del citado artículo 1.516, que el acreedor acepta la división de la deuda. Sin embargo, aún cabe destacar que, de acuerdo al inciso final del artículo 1.522 del mismo Código, "La parte o cuota del codeudor insolvente se reparte entre todos los otros a prorrata de las suyas, comprendidos aun aquellos a quienes el acreedor haya exonerado de la solidaridad".

No obstante, y como indicaremos más adelante, este punto debe ser matizado en tanto los pagos a ser efectuados a los agentes (esencialmente comisiones y remuneraciones) son normalmente de cargo del deudor, quien los asume en el propio texto contractual.

b. Mandato específico

Las modalidades de agencia previstas en el citado artículo $18^{\circ}$ de la Ley No 20.190 suponen mandatos específicos, en el sentido de que la gestión de negocios encomendada solo se refiere a "en el otorgamiento o gestión de sus créditos [en el caso del "banco agente"], o

\footnotetext{
58 Sobre la justificación de esta regla, que se aleja de la articulación de las obligaciones asumidas por los mandantes en el contexto de un contrato civil, STITchkin (2009) pp. 223 y 224 ensaya como justificación la necesidad de asegurar el resultado de las transacciones mercantiles.

59 Stitchkin (2009) p. 224. En el mismo sentido, Ramos Pazos (1999) pp. 90 y 91.
} 
en la constitución, modificación o extinción de sus garantías [en el caso del "agente de garantías"], o en ambos, y para el ejercicio mancomunado de los derechos que emanen de tales créditos o garantías".

El ámbito de las facultades del agente es aquel que se señale expresamente en el contrato de "agencia" (o "comisión"), usualmente contenido en una o varias cláusulas del mismo contrato de crédito sindicado. Pero el legislador ha tenido la prudencia de señalar que, en ausencia de un contenido específico del mandato, deberá entenderse que el mandatario solo tiene facultades de mera administración y conservación (artículo $3^{\circ}$ del artículo $18^{\circ}$ de la Ley No 20.190).

En el ámbito del "agente de garantías", ello implica la realización de todas las gestiones conducentes a la constitución de las garantías, sea concurriendo a su otorgamiento o realizando las actuaciones necesarias para su perfeccionamiento, y a su ejecución. A mayor abundamiento, el artículo $2^{\circ}$ agrega un importante catálogo de actuaciones que forman parte de la naturaleza de esta clase de negocios. Así, constituyen gestiones a realizar por el agente en relación a las garantías constituidas para la seguridad de los créditos: (i) su aceptación por cuenta del conjunto de acreedores actuales y futuros; (ii) la aceptación de sus modificaciones o sustituciones; (iii) el consentimiento para su alzamiento; (iv) el ejercicio de los derechos que de ellas emanen, incluyendo las facultades para cobrar y percibir, incluso judicialmente, otorgar carta de pago y cancelación y alzarlas ilimitadamente; $(v)$ recibir la cosa dada en prenda (con desplazamiento) para el perfeccionamiento del contrato; y (vi) recibir las citaciones y notificaciones que de acuerdo a la ley deben practicarse respecto de los acreedores hipotecarios o prendarios.

En el caso del "agente de créditos", sin embargo, la referencia a las facultades de conservación no parece encajar muy bien con el tipo de actuaciones que generalmente se les encomienda en las operaciones de crédito sindicadas. Como hemos indicado, el "banco agente" no tiene por objeto velar por la seguridad y conservación de los créditos, sino simplificar y aunar la actuación de las entidades prestamistas mediante la configuración de un único interlocutor. Así, mayor sentido tiene hablar de las facultades administrativas del "banco agente", que corresponden a las gestiones que debe desempeñar para la correcta ejecución del contrato, y que de algún modo se vislumbran en la definición de la agencia de créditos contenida en el artículo $1^{\circ}$ del artículo $18^{\circ}$ de la Ley No $^{20.190}$. La falta de menciones supletorias respecto a su encargo por parte de la citada ley se justifica en que, como hemos señalado, su mensaje solo pretendía cubrir la figura del "agente de garantía", de modo que el detalle de la comisión encargada al "banco agente" no revistió especial preocupación por parte del legislador, quedando genéricamente entregado a los pactos que alcancen las partes.

\section{c. Comisión naturalmente remunerada}

Por su naturaleza, el artículo $3^{a}$ del artículo $18^{\circ}$ de la Ley $N^{o} 20.190$, las agencias de crédito y garantías son mandatos de carácter remunerado, referencia que reincide en la calificación onerosa de la comisión mercantil (artículo 239 del Código de Comercio). No siendo de la esencia de la comisión, el propio artículo $3^{\circ}$ aclara que se admite "pacto en contrario", permitiendo que el agente actúe gratuitamente a favor de sus mandatarios. 
De no ser así, en un principio, los obligados a la remuneración deberían ser las entidades mandantes, órbita en la que tiene importancia la regla de solidaridad pasiva impuesta en el artículo 290 del Código de Comercio. Sin embargo, en las operaciones sindicadas suele estipularse que las comisiones que devenguen estas formas especiales de mandato no corresponden a los mandantes, sino propiamente al prestatario. Los costos de la operatividad del contrato no son soportados por los acreedores, sino, como cualquier otro costo derivado de esta clase de financiamiento, por quien recibe y se beneficia de los fondos.

Esta idea nos reconduce a una estructura necesariamente triangular de las agencias de créditos y garantías. Circunstancia que queda de alguna manera reflejada en el artículo $1^{\circ}$ de la Ley $\mathrm{N}^{\circ}$ 20.190, que dispone que "La agencia debe ser expresamente aceptada por el deudor". Pero ello no implica que el deudor pase a ser parte del mandato, a lo menos en lo que se refiere a las obligaciones de gestión del mandatario, sino solo, y a lo sumo, en las obligaciones de pago de la remuneración en los términos previamente indicados.

\section{d. Contrato solemne}

Conforme al artículo $4^{\circ}$ del artículo $18^{\circ}$ de la Ley № 20.190 , estas formas especiales de mandato tienen el carácter de solemnes, en el sentido que su perfeccionamiento está sujeto a su celebración por medio de escritura pública o privada, en este último caso, debiendo las firmas ser autorizadas por un notario y el instrumento protocolizado. Adicionalmente, y a efectos de facilitar la celebración de esta clase de negocios con entidades extranjeras, se admite también, para el caso que el instrumento haya sido suscrito en el extranjero, que este sea debidamente legalizado, procediéndose a protocolizar en Chile una copia del mismo. La designación del agente y su reemplazo se efectuarán en los mismos instrumentos señalados.

En cualquier caso, debemos entender que se trata de formalidades establecidas en consideración a la naturaleza del acto o contrato, de manera que su infracción supondrá su nulidad absoluta (artículo 1.682 del Código Civil). No obstante, cabe puntualizar que podría explorarse la posibilidad de que tal nulidad pueda estar sujeta a la idea de "conversión del acto nulo" 60 , especialmente si consideramos que se cumplen todos los requisitos para su consideración como comisión mercantil, contrato que no requiere de formalidades especiales para su perfeccionamiento. En este sentido, creemos, la principal diferencia estará dada por el hecho de que en la comisión mercantil, la cesión del crédito por parte de alguno de los comitentes no implicará la necesaria cesión de su posición contractual en el mandato, efecto que sí podría deducirse de la lectura del artículo $2^{\circ}$ del artículo $18^{\circ}$ de la Ley № 20.190 .

\subsubsection{Sobre la terminación de las agencias de "crédito" y de "garantías"}

Un aspecto que merece la pena estudiar separadamente, se refiere a las normas específicas dadas para la terminación de estas formas de "agencia" en el artículo $18^{\circ}$ de la Ley $\mathrm{N}^{\circ} 20.190$, en razón de su particularidad y a la necesaria estabilidad del vínculo de cooperación y actuación común ${ }^{61}$. De este modo, el artículo $1^{\circ}$ dispone que "La agencia

\footnotetext{
60 Vial del Río (2003) pp. 288-290.

61 Obsérvese que la regulación especial no contiene normas relativas a la renuncia del agente, por lo que deben entenderse aplicables las reglas generales previstas en los artículos 242 del Código de Comercio y 2.161 del Có-
} 
debe ser expresamente aceptada por el deudor. Prestado este consentimiento, es irrevocable por la sola voluntad del deudor". En consecuencia, la aceptación expresa del deudor-que puede ser prestada tanto en el propio texto del contrato como en un momento diferente- no solo configura la estructura triangular de este mandato, sino que fija el momento en que este se hace irrevocable por la sola voluntad del deudor.

Esta norma llama en algo la atención, puesto que la revocabilidad del mandato se refiere a la posibilidad de que el mandante o comitente ponga término anticipado al contrato, liberando al mandatario o comisionista de sus obligaciones (artículo 241 del Código de Comercio). Y, como hemos señalado, la presencia de la estructura triangular de estas agencias no alcanza a configurar al deudor como mandante del agente, ni siquiera en los casos en que la referencia esté dada a la diputación para el cobro de la deuda de manera conjunta entre acreedores y deudores (artículo 1.584 del Código Civil), por cuanto esta regla se refiere a la posibilidad de revocación por parte de quien ocupa la posición activa de la obligación (el acreedor). La norma tampoco puede ser interpretada a contrario sensu, en cuanto no podría entenderse que el deudor pudiese revocar la comisión antes de su aceptación a la misma.

Por su parte, el inciso primero del artículo $5^{\circ}$ del mismo cuerpo legal agrega que " $E l$ contrato de agencia de créditos o garantías es revocable anticipadamente o susceptible de modificación, únicamente en los términos contemplados en el mismo. Si al efecto nada precisare, se entenderá que es modificable o terminable por la voluntad de acreedores que representen al menos las dos terceras partes del saldo en capital adeudado bajo el contrato". Esta norma modera de alguna manera la estricta regla de irrevocabilidad de la comisión contenida en el artículo 241 del Código de Comercio, cuando el negocio encargado interesa al comisionista o a terceros. Sin embargo, nuevamente nos encontramos en el campo de una regla supletoria a la voluntad de las partes, en el sentido que es el propio contrato el que deberá determinar los requisitos para la revocación anticipada o modificación del mandato por parte de los bancos acreedores. La idea de la pluralidad de partes y la necesidad de unificar actuaciones renace en este aspecto hasta construir una regla dispositiva que requiere de la existencia de un determinado porcentaje para proceder a tal revocación o modificación. Lo elevado del mismo da la impresión de una pretensión previa por parte del legislador de asegurar la estabilidad de la actuación conjunta (o de la colectividad a la que hace referencia el artículo 1 del artículo 14 de la Ley $\mathrm{N}^{\circ}$ 20.190), alejándola de las controversias puntuales que pudiesen desarticular la lógica del sindicato de acreedores ${ }^{62}$.

Lo que sí llama la atención es la referencia a la posibilidad de modificar los términos del mandato conforme a la misma lógica de la revocación. Podría dar la impresión de que, salvo pacto en contrario, las dos terceras partes de los acreedores podrían alterar los términos del encargo, sin considerar la voluntad del agente. No nos parece esta una inter-

digo Civil, especialmente respecto a la necesidad de aviso, sus limitaciones y eventuales responsabilidades. Vid., por todos, Sandoval (2003) p. 535.

62 Con esta regla también puede entenderse que se hace excepción a la exigencia de unanimidad para revocación, en caso de pluralidad de mandantes que tuviesen un interés común manifestado en la intención de que el negocio se ejecutase por medio del mandatario, conclusión a la que llega Stitchin (2009) p. 465, haciendo referencia (en pie de página) a los artículos 2.072 y 2.074 del Código Civil. 
pretación coherente, en tanto atentaría en contra del artículo 1.545 del Código Civil. Preferimos la interpretación que supone que aquella voluntad será siempre necesaria y que la referencia al quórum solo se refiere al régimen de mayorías que se aplica a la pluralidad de mandantes.

Finalmente, el artículo $6^{\circ}$ del artículo $18^{\circ}$ de la Ley No 20.190 dispone que " $E l$ reemplazo del agente deberá hacerse al amparo de los términos y condiciones establecidos en el contrato, y en su silencio, deberá ser acordado por los acreedores que representen a lo menos la mayoría absoluta del saldo adeudado bajo el contrato. No podrá revocarse el mandato al agente, si simultáneamente no se designa un reemplazante, con las formalidades correspondientes.// El reemplazo de agente podrá hacerse en contra de su voluntad. Si no hubiere dado motivo a su reemplazo, por su culpa, tendrá derecho a ser indemnizado por el perjuicio que se le cause con su remoción, salvo en cuanto se hubiere pactado otra cosa". La diferencia entre el supuesto de revocación de la agencia contenida en el artículo $5^{\circ}$ del artículo $18^{\circ}$ de la Ley № 20.190 y el reemplazo previsto en el artículo $6^{\circ}$ se encuentra en que, en este último caso, será siempre necesaria la designación de un nuevo agente. Ello supone que las partes desean mantener el mecanismo de actuación conjunta, aunque pretendan revocar el mandato otorgado a quien ha oficiado hasta el momento como "banco agente". De ahí que el quórum supletoriamente previsto por el legislador sea menor al del caso de mera revocación, solo requiriendo de la mayoría absoluta del saldo insoluto. En caso de que se proceda efectivamente al reemplazo, la designación del nuevo agente estará sujeta a iguales formalidades que el contrato de agencia (artículo 4 del artículo 18 de la Ley $\mathrm{N}^{\circ} 20.190$ ).

\section{CONCLUSIONES}

El contrato de crédito sindicado es una forma de estructurar una operación de financiamiento que no limita su caracterización por la sola existencia de una pluralidad de entidades prestamistas, sino que se encuentra especialmente centrada en la creación de un mecanismo de coordinación entre aquellas en su relación de crédito con el deudor.

La referida forma de coordinación supone reconocer la tensión existente entre la independencia de los créditos, la dilución del riesgo comercial de la operación y el vínculo de cooperación entre las entidades acreditantes, todos factores que incidirán en la redacción del texto contractual. La forma en que se coordinen todos dichos elementos (al amparo del concepto del "sindicato de bancos") dependerá de las circunstancias específicas del financiamiento, aun cuando puedan avistarse ciertos puntos comunes, a los que hemos hecho referencia en el presente artículo.

El ordenamiento jurídico chileno no contiene un reconocimiento expreso a esta clase de financiamiento, salvo en lo que se refiere a la unidad de actuación entregada al "banco agente" y al "agente de garantías", de conformidad a los términos del artículo $18^{\circ}$ de la Ley $\mathrm{N}^{\circ}$ 20.190. La referida disposición otorga un marco normativo general (muchas veces supletorio) que pretende aliviar los problemas prácticos que había dado cuenta el mercado financiero previo a su publicación, particularmente referidos a la estabilidad del mandato común y a la administración de las garantías constituidas para asegurar el cumplimiento de las obligaciones emanadas del contrato de crédito sindicado. 
La citada regulación supone -sin incidir especialmente en ellos- los elementos característicos del crédito sindicado, aun cuando se detiene primordialmente en el extremo de la unidad de actuación que supone el vínculo de cooperación. Los demás factores (en particular, algunas variantes de la dilución del riesgo) son aún dejados a la libertad de pactos y al ingenio de la práctica comercial.

\section{BIBLIOGRAFÍA CITADA}

Amesti Mendizábal, Christi (1994): "El contrato de crédito sindicado y el crédito subasta”, en AA.VV., en: Alonso Ureba, Alberto y Martínez-Simancas Sánchez, Julián (dirs.), Derecho de Mercado Financiero, Tomo II, Vol. I (Madrid, Civitas), pp. 401-437.

Blaise, Jean Bernard y Fouchard, Philippe (1981): "Le valeur juridique de la syndication", en: AA.VV., en Les Euro-credits: un Instrument du Systéme Bancaire pour le Financement International (París, Librairies Techniques) 764 pp.

Contreras Strauch, Osvaldo (2005): Instituciones de Derecho Comercial, Tomo II (Santiago de Chile, LexisNexis) 1070 pp.

De Gispert Pastor, María Teresa (1986): Los Créditos Sindicados: su Integración en el Sistema Jurídico Español (Barcelona, Bosch) 325 pp.

Donaldson, T.H. (1979): Lending in International Commercial Banking (Londres, The MacMillan Publishers Ltd) 187 pp.

Fernández de la Gándara, Luis (1997): "Los préstamos y créditos sindicados con interés variable”, en: Calvo Caravaca, Alfonso L. y Fernández de la Gándara, Luis (dirs.), Contratos Internacionales (Madrid, Tecnos), pp. 864-902.

Ferré Molto, Miguel (1998): “Operaciones bancarias sindicadas", en: Nieto Carol, Ubaldo (dir.) Contratos Bancarios y Parabancarios, Lex Nova, Valladolid, pp. 595-622.

Figueroa Yáñez, Gonzalo (2008): El Patrimonio (Santiago de Chile, Editorial Jurídica de Chile) 686 pp.

Flaquer Ruitort, Juan (1992): El contrato de Crédito Subasta (Barcelona, J.M. Bosch Editor) $504 \mathrm{pp}$.

Garrigues, Joaquín (1958): Contratos Bancarios (Madrid, [s.n.]) 694 pp.

Hughes, Martin (2006): Legal Principles in Banking and Structured Finance (West Sussex, Tottel) 263 pp.

Mugasha, Agasha (2007): The Law of Multi-bank Financing. Syndicated Loans and the Secondary Loan Market (Nueva York, Oxford University Press) 650 pp.

Oldnall, James y Clark, Michael (2010): “The age of consent", Journal of International Banking Law and Regulation, pp. 89-93.

Puelma Accorsi, Álvaro (1971): Estudio Jurídico sobre Operaciones Bancarias (Santiago de Chile, Editorial Jurídica de Chile) 349 pp.

Ramos Pazos, René (1998): De las Obligaciones (Santiago, Editorial Jurídica de Chile) 535 pp.

Rawlings, Philip (2009): "The management of loan syndicates and the right of individual lenders", Journal of International Banking Law and Regulation, pp. 179-185.

Ríos LabBÉ, Sebastián (2011): "Reflexiones sobre el régimen de la cesión convencional de contratos”, en AA.VV., en: Corral Talciani, Hernán, Guzmán Brito, Alejandro, 
Pizarro Wilson, Carlos, Rodríguez Pinto, María Sara, Turner Saelzer, Susan, Varas Braun, Juan Andrés y Departamento de Derecho Privado de la Universidad de Concepción (coords.), Estudios de Derecho Civil, Tomo III, (Santiago de Chile, Abeledo Perrot /LegalPublishing) pp. 485-497.

Rhodes, Tony (2004): Syndicated Lending. Practice and Documentation (Londres, Euromoney Books) 578 pp.

Sandoval López, Ricardo (2003): Contratos Mercantiles (Santiago de Chile, Editorial Jurídica de Chile) $744 \mathrm{pp}$.

Stitchrin Branover, David (2009): El Mandato Civil, Quinta edición actualizada por Gonzalo Figueroa Yáñez (Santiago, Editorial Jurídica de Chile) 534 pp.

Tapia Sánchez, María Rosa (2007): "El contrato de préstamo bancario. El préstamo sindicado”, en: Gadea Soler, Enrique y Sequeira Martín, Adolfo (coord.), La Contratación Bancaria (Madrid, Dykinson) Madrid, pp. 754-772.

Vial del Río, Víctor (2003): Teoría General del Acto Jurídico, Quinta edición actualizada (Santiago de Chile, Editorial Jurídica de Chile) 407 pp.

Zunzunegui, Fernando (2000): Derecho del Mercado Financiero, Segunda edición (Madrid, Marcial Pons) 789 pp.

\section{NORMAS CITADAS}

Código Civil.

Código de Comercio.

Ley No 18.010, que establece normas para las operaciones de crédito y otras obligaciones de dinero que indica. Diario Oficial, 27 de junio de 1981.

Ley N ${ }^{\circ}$ 18.045, de Mercado de Valores. Diario Oficial, 22 de octubre de 1981.

Decreto con Fuerza de Ley $\mathrm{N}^{\circ} 3$, que fija texto refundido, sistematizado y concordado de la Ley General de Bancos y de otros cuerpos legales que se indican. Diario Oficial, 19 de diciembre de 1997.

Ley No 20.190, que introdujo adecuaciones tributarias e institucionales para el fomento de la industria de capital de riesgo y continuó el proceso de modernización del mercado de capitales. Diario Oficial, 5 de junio de 2007.

Boletín No. 3278-05, que contiene la historia de la Ley $N^{\circ} 20.190$, que introdujo adecuaciones tributarias e institucionales para el fomento de la industria de capital de riesgo y continuó el proceso de modernización del mercado de capitales. Disponible en http:// www.bcn.cl/histley/lfs/hdl-20190/HL20190.pdf [fecha de consulta: 5 de enero de 2012]. 